\title{
Dual Band David Fractal Microstrip Patch Antenna for GSM and WiMAX Applications
}

\author{
Jacob Abraham, Thomaskutty Mathew \\ School of Technology and Applied Science, Mahatma Gandhi University Regional Centre, Kochi, India \\ Email: tjacobabra@gmail.com, mwrfgroupstas@gmail.com
}

Received 15 May 2015; accepted 6 June 2015; published 9 June 2015

Copyright (C) 2015 by authors and Scientific Research Publishing Inc.

This work is licensed under the Creative Commons Attribution International License (CC BY). http://creativecommons.org/licenses/by/4.0/

(c) (i) Open Access

\begin{abstract}
The design and development of a proximity fed dualband microstrip patch antenna based on David fractal geometry are presented. David fractal microstrip antenna offers good performance in the $1.754-1.816 \mathrm{GHz}$ and $3.37-3.415 \mathrm{GHz}$ bands and is suitable for GSM 1800, WiMAX applications. The use of David fractal geometry offers miniaturization of the antenna structure. The proposed first iteration fractal configuration is fabricated and measured results along with simulation results are presented. Good radiation patterns and moderate gain are also obtained.
\end{abstract}

\section{Keywords}

Microstrip, David Fractal, Proximity Feed, Dualband

\section{Introduction}

Nowadays antennas with multi-band and smaller dimensions than conventional ones are preferred. Multiple resonances with good gain in a single patch are not directly attainable in simple microstrip antenna. Various techniques have been utilized in the antenna research to reduce size and to achieve multi-band characteristics in a single patch. A review of various techniques to minimize the antenna size is given in Ref. [1]. In [2] miniaturization of the patch antenna is obtained by combining two techniques, inserting slots as inductive loading and making some short point in the middle of the patch. In [3] a technique is proposed for reducing the size of a shorted microstrip patch antenna where notches are placed near the shorting pin and feed. And another technique is employed to achieve antenna size reduction by increasing the electrical length of the antenna [4]. Numerous research papers have reported for achieving dual band operation of microstrip antennas. A novel design of a dual band planar monopole antenna, consisting of a rectangular strip ring with double meander-lines and a top loaded vertical strip, is presented in [5]. In [6] slot antennas were used to achieve multiband characteristics. The conventional monopole CPW fed antenna with a U shaped strip and a pair of L slits in the ground plane to develop 
multi-band antenna is presented in [7]. In [8] multi-band probe fed stacked patch antenna for global navigation satellite systems is reported which is intensively used both in civilian and military application.

Recently fractal techniques have been widely applied to antenna design to reduce the antenna size and to achieve multi-band behavior. Fractal antennas can be physically small but have electrically long lengths in small packages. Fractal geometry composed of multiple iterations of a single elementary shape, can be continued infinitely thus forming a shape within a finite boundary but of infinite length or area. This compactness in property is highly desirable in mobile wireless applications. The advantages of fractal antenna compared with a standard microstrip antenna are centered on miniaturization and bandwidth. Various geometries have been utilized to develop fractal antennas in order to have multi-band characteristics and miniaturization. Much intensive researches have been done in recent years to develop fractal antennas: long periodic fractal Koch antenna [9] and bow shaped fractal helix antenna [10]. A modified Minkowski fractal geometry for multiband operation is presented in [11]. Koch-like curve and Sierpinski Gasket are synchronized in a way, comprising so called Sierpinskized Koch-like sided bow-tie (SKLB) multi-fractal to achieve size reduction and multi-frequency use [12]. A plus shaped slotted fractal antenna with first and second iteration is reported in [13] that gives a good size reduction and enhanced band width.

Compared with the conventional square and circular patch antennas nowadays a lot of fractal antennas are developed with pentagon and hexagon shaped patches. A slotted grounded hexagonal microstrip antenna with a parasitic element is presented in [14]. Pentagonal shape for basic fractalization combined with inner sides etched with Koch fractal is reported [15] with achievement of good size reduction. A circular-hexagonal fractal antenna where iterations of a hexagonal slot inside a circular metallic patch is done to achieve multi-band behavior [16]. Another hexagonal fractal microstrip antenna where iterations of hexagonal slot inside a hexagonal patch with multi-band and broad band characteristics has been demonstrated in [17]. In [18] a CPW feed dual band fractal antenna structure is formed by inscribing a hexagonal slot within a circle.

The recent growth and rapid development of mobile communication systems and devices operating at multiple frequency bands have led to the requirement of antennas which support multi-band or wideband operation. Various wireless communication services have been available which may use frequency spectrum allocation like WiMAX/Wi-Fi etc. along with GSM communication system. This leads to development of multi-band antennas, where GSM mobile communication as well as WiMAX/Wi-Fi can be used simultaneously. Various research papers have reported about dual band antennas that are suitable for above mentioned application [19] [20]. The WiMAX standard has the advantage of allowing wireless connection between a base transceiver station and thousands of subscribers without requiring the subscriber to be in a direct line of sight with the station, called non line of sight communication [NLOS]. This gives users the mobility to move around within a broad coverage area and still be connected to the network, to provide high speed internet access. The advantage of multi-band antenna is the ability to integrate several frequency bands on one single antenna, making it useful for several frequency ranges.

In this paper, a novel hexagonal fractal microstrip antenna is proposed for multi-band applications. David fractal [21] concept is introduced into a hexagon shaped microstrip patch antenna to obtain multi-band behavior and miniaturization. This hexagon shaped dual band David fractal microstrip patch antenna resonates at $1.8 \mathrm{GHz}$ and $3.4 \mathrm{GHz}$. The first frequency is used for GSM cellular communication and the second frequency is used for WiMAX applications. In order to obtain antenna, with optimized parameters, simulation studies were carried out using CST microwave studio. In the proposed antenna, at upper resonance frequency the maximum power received will be at $43^{\circ}$ away from the bore sight, and these characteristics may find applications in non-line of sight communication including WiMAX [22].

\section{David Fractal Geometry}

The fractal design of antennas results from the blend of two discipline, electromagnetic theory and fractal geometry. The term fractal and fractal dimensions were coined by B. Mandelbrot [23]. Mandelbrot defined a fractal as a rough or fragmented geometric shape that can be subdivided in parts each of which is a reduced copy of the whole. The David fractal is a class of fractal geometries whose recursive procedure is demonstrated in Figure 1. The David fractal pattern is formed from the basic hexagon shaped patch or the initiator as in Figure 1(a) by dividing it in to six smaller hexagons, six equilateral triangles and a David star at the center; the triangles and the star are removed. It results in first iteration level as shown in Figure 1(b). The second iteration as shown in 
Figure 1(c) is a reduced copy of the design of the first iteration repeated in each smaller hexagon. From the iteration stages it is observed that at the end of the first iteration stage six smaller hexagons with equal dimensions are produced and at the end of the second iteration stage thirty six further smaller hexagons are produced. The six hexagons of the first iteration stage are fractalized in to thirty six hexagons.

\section{Antenna Configuration}

The antenna is fabricated onan FR-4 substrate of thickness $1.6 \mathrm{~mm}$ with relative permittivity of 4.4 and loss tangent of 0.002. The zeroth iterated level antenna consists of a hexagonal patch, with each side of the patch having a length of $24.6 \mathrm{~mm}$, resonating at $1.8 \mathrm{GHz}$ called the initiator as shown in the Figure 1(a). In this antenna proximity feeding technique is employed. The antenna is fed by $50 \mathrm{ohm}$ microstrip feed line with a width of $3.03 \mathrm{~mm}$ and length of $31 \mathrm{~mm}$. In order to achieve multiband characteristics David fractal geometry is introduced in to the hexagon shaped patch. Figure 2 illustrates the structure of the proposed dual band miniaturized David fractal first iteration level antenna. The fabricated prototype of the David fractal antenna is shown in Figure 3. The return loss variations with frequency of the first iterated level David fractal antenna shows dual band characteristics. It has two resonant frequencies at $1.55 \mathrm{GHz}$ and $2.64 \mathrm{GHz}$. The dual band antenna is optimized so that the simulated David fractal antenna produces two resonances at $1.8 \mathrm{GHz}$ and $3.4 \mathrm{GHz}$. The lower resonant frequency is suitable for GSM mobile communication and the upper resonant can be used for WiMAX applications in $4 \mathrm{G}$ phones, which is used to provide high speed internet access for non-line of sight environments. In this case resonant frequency optimization is done where optimization parameter is the side length of the hexagonal patch antenna. The detailed dimensions of the antenna are shown in Table 1. The design of the antenna was optimized using CST Microwave Studio Suit 2010.

\section{Measurement Set-Up}

The measurements were carried out in an anechoic chamber using HP 8510C Network Analyzer. The chamber was arranged such that the source remains stationary as the antenna under test (AUT) rotates. A standard horn antenna is used as the reference antenna for the measurements. The antenna under test is placed in an antenna

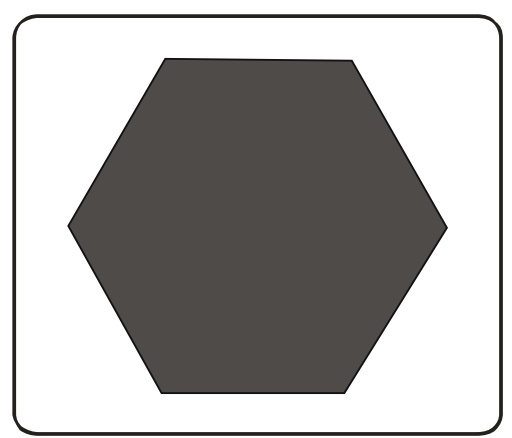

(a)

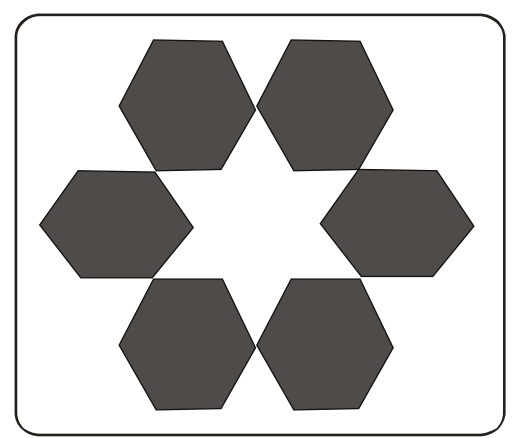

(b)

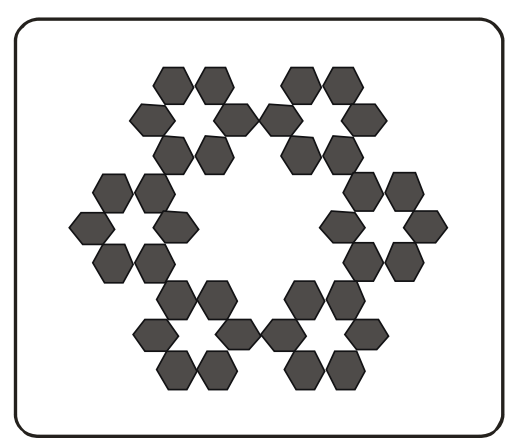

(c)

Figure 1. Different iteration stages of David fractal.

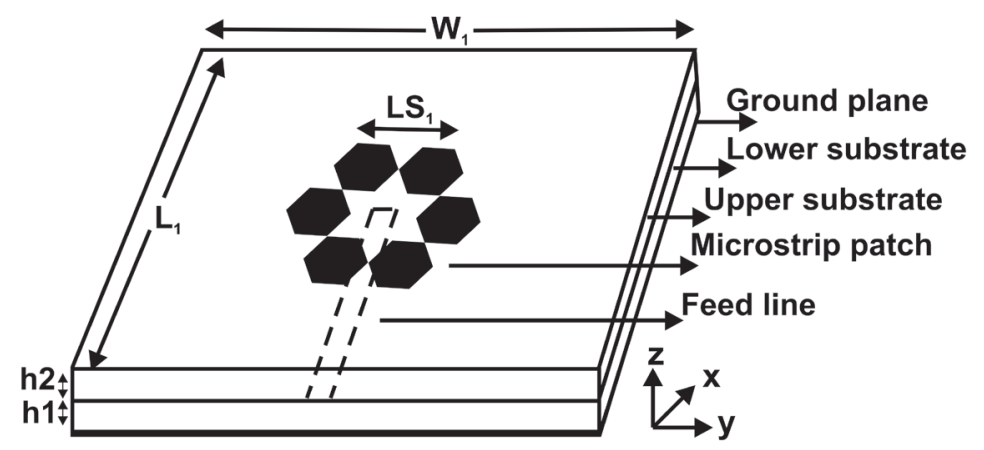

Figure 2. Structure of the proposed dual band fractal antenna. 


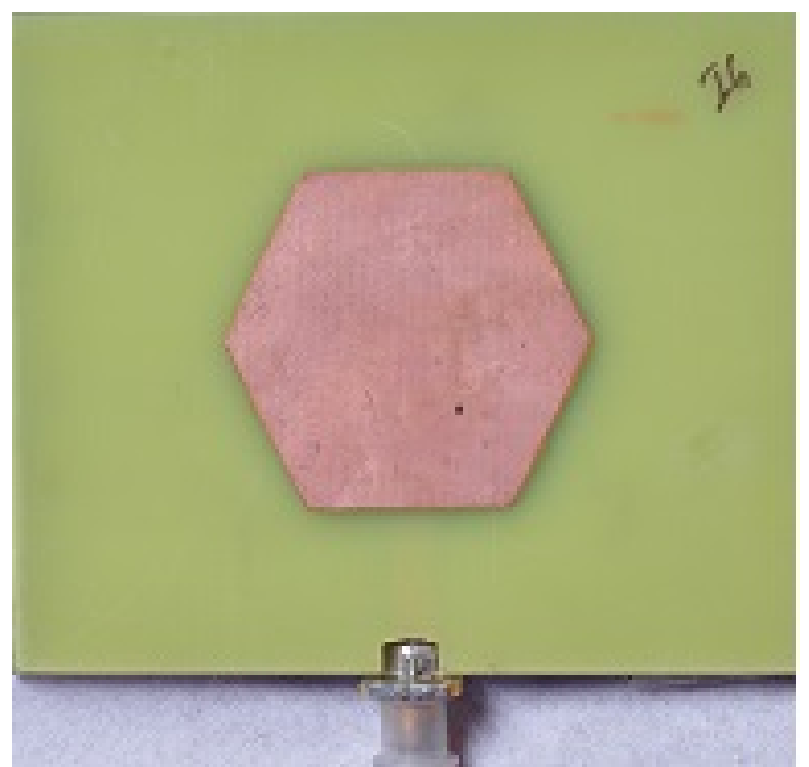

(a)

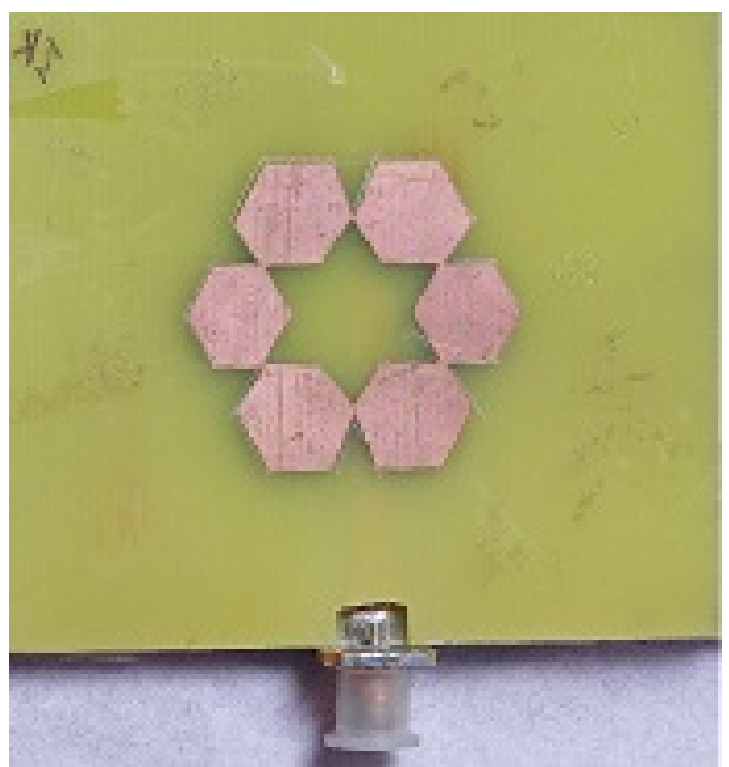

(b)

Figure 3. Photograph of the fabricated antenna: (a) Zeroth iteration level David fractal antenna; (b) First iteration level David fractal antenna.

Table 1. Dimensions of the dual band fractal antenna (units: $\mathrm{mm}$ ).

\begin{tabular}{cccccc}
\hline Parameter & Value & Parameter & Value & Parameter & Value \\
\hline $\mathrm{L}_{1}$ & 72 & $\mathrm{~W}_{1}$ & 84 & $\mathrm{LS}_{1}$ & 21.4 \\
\hline
\end{tabular}

holder, which is set to rotate the antenna in small steps of $1^{\circ}$ to obtain a $360^{\circ}$ radiation pattern. The microwave materials that covers the wall, top and bottom surfaces absorbs electromagnetic energy so that the anechoic chamber to replicates a space equivalent.

\section{Results and Discussions}

Figure 4 shows the simulated and measured return loss variation with frequency for the $1^{\text {st }}$ level iterated David fractal hexagon patch antenna. It can be seen that the $-10 \mathrm{~dB}$ bandwidth for the measured return loss is $62 \mathrm{MHz}$ (1.754 - $1.816 \mathrm{GHz})$ and $45 \mathrm{MHz}(3.37$ - $3.415 \mathrm{GHz})$ respectively, which can cover GSM mobile communication system and WiMAX applications in the $4 \mathrm{G}$ mobile phones. Table 2 shows comparison between simulated and measured antenna parameters for the first iterated level David fractal microstrip patch antenna. The discrepancy between the measured and simulated results is due to fabrication tolerance and small air gap between dielectric layers.

Figure 5 illustrates the simulated surface current distribution on the antenna the two operating frequencies. At lower resonant frequency current density is concentrated along the inner region of the radiating patch and for the upper resonant frequency; the current density is concentrated along the outer regions of the radiating patch while small amount of current is flowing at the inner areas of the patch.

The co-polar and cross polar radiation patterns have been measured at two different frequencies of $1.79 \mathrm{GHz}$ and $3.385 \mathrm{GHz}$ for both $\mathrm{E}$ and $\mathrm{H}$ plane. The radiation pattern data are normalized in order to plot the co-polar and cross polar patterns in one graph. The measured far field radiation patterns of the dual band David fractal first level iterated antenna in the E plane ( $\mathrm{y}-\mathrm{z}$ plane) and $\mathrm{H}$ plane ( $\mathrm{x}-\mathrm{z}$ plane) are plotted at the frequency of 1.79 $\mathrm{GHz}$ and $3.385 \mathrm{GHz}$ is shown in Figure 6 and Figure 7 respectively. At the lower resonance frequency (1.79 $\mathrm{GHz}$ ) the maximum power was received by the antenna at the bore sight direction while at the upper resonance frequency $(3.385 \mathrm{GHz})$ the maximum power was received at angle $43^{\circ}$ with respect to bore sight. The upper band characteristics are suitable in non-line of sight applications. 


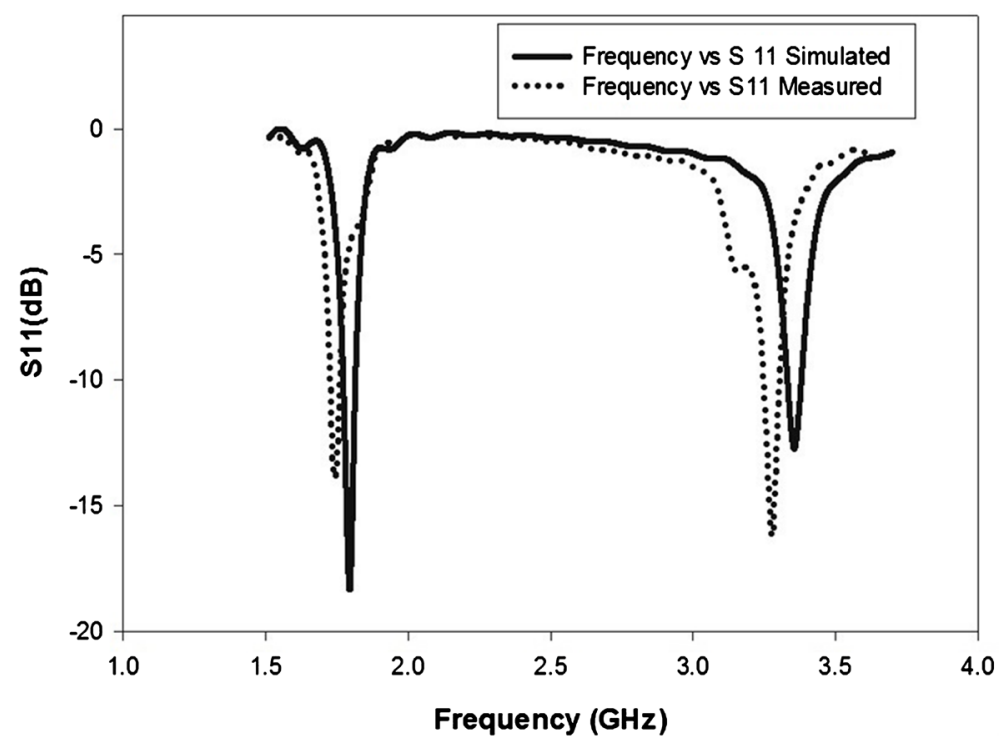

Figure 4. Measured and simulated return loss for the proposed antenna.

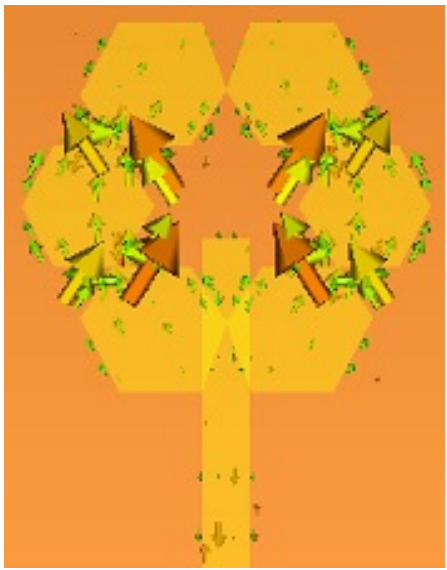

(a)

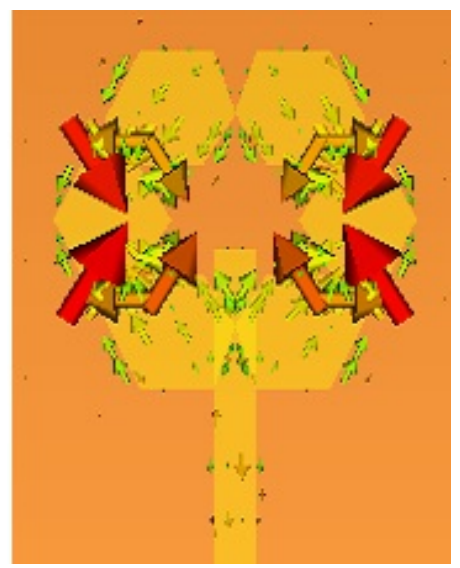

(b)

Figure 5. Simulated surface current distributions on the radiating path for the proposed antenna at (a) first resonance frequency $1.8 \mathrm{GHz}$ and (b) second resonance frequency $3.4 \mathrm{GHz}$.

Table 2. Simulated and measured results.

\begin{tabular}{|c|c|c|}
\hline Parameter & Simulated & Measured \\
\hline Resonance frequency $\mathrm{f}_{1}(\mathrm{GHz})$ & 1.8 & 1.79 \\
\hline Bandwidth $_{1}(\mathrm{MHz})$ & 55 & 62 \\
\hline $\mathrm{S}_{11}(\mathrm{~dB})$ & -18.7 & -13.54 \\
\hline Gain (dBi) & 6.93 & 6.5 \\
\hline Resonance frequency $\mathrm{f}_{2}(\mathrm{GHz})$ & 3.4 & 3.385 \\
\hline Bandwidth $_{2}(\mathrm{MHz})$ & 31 & 45 \\
\hline $\mathrm{S}_{11}(\mathrm{~dB})$ & -14.3 & -16.48 \\
\hline Gain (dBi) & 5.3 & 4.9 \\
\hline
\end{tabular}




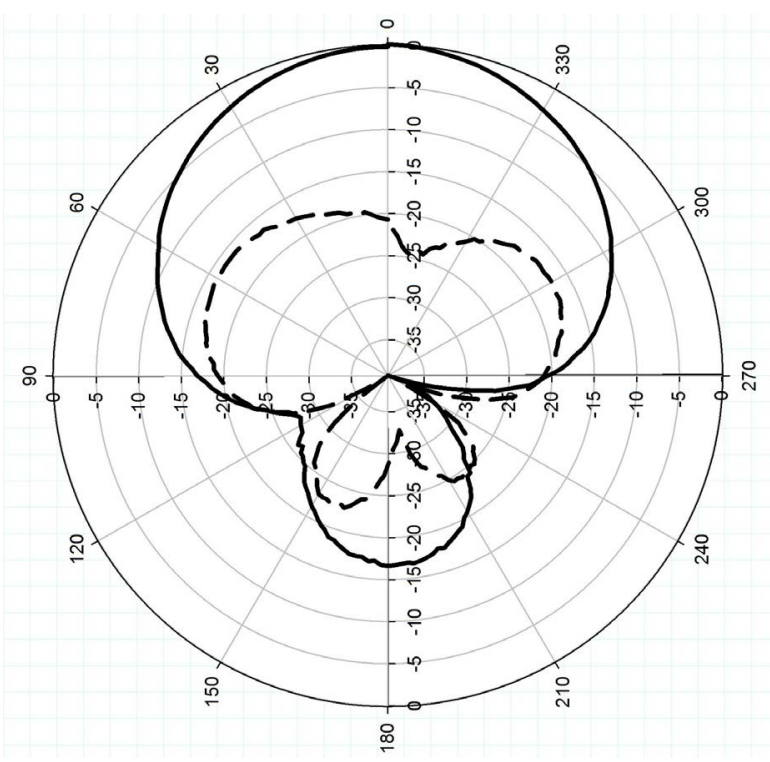

(a)

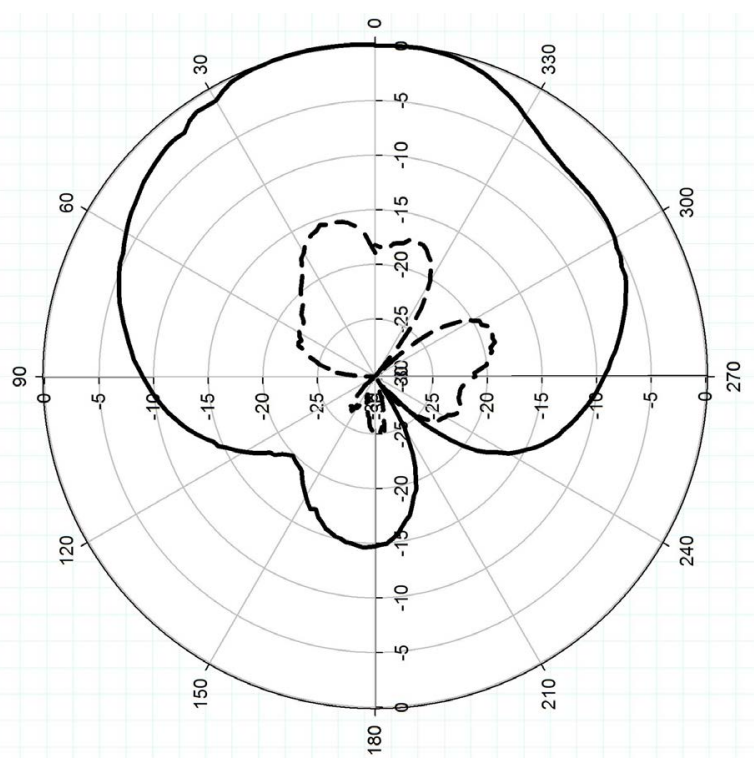

(b)

Figure 6. Measured normalized radiation patterns of the antenna at resonant frequency $1.79 \mathrm{GHz}$. (a) E plane; (b) H plane (co-polarized, solid line and cross polarized, dashed line. (a) y-z plane; (b) $\mathrm{x}-\mathrm{z}$ plane.

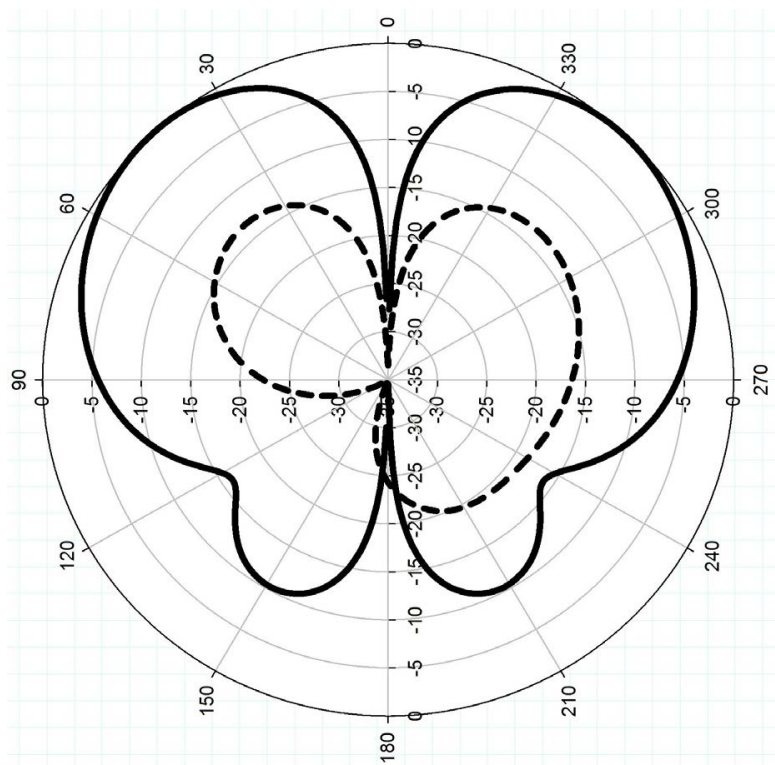

(a)

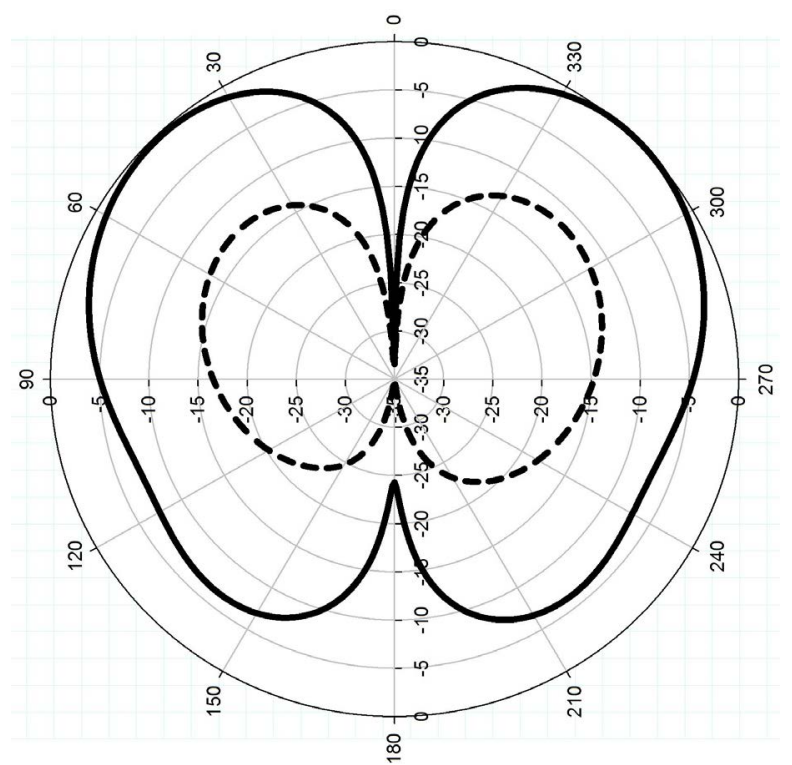

(b)

Figure 7. Measured normalized radiation patterns of the antenna at resonant frequency $3.385 \mathrm{GHz}$. (a) E plane; (b) H plane (co-polarized, solid line and cross polarized, dashed line. (a) $\mathrm{y}$-z plane; (b) $\mathrm{x}-\mathrm{z}$ plane.

The measured gain of the antenna is $6.5 \mathrm{dBi}$ at the lower resonant frequency and $4.9 \mathrm{dBi}$ at the upper resonant frequency. The upper band characteristics will find useful in the non-line of sight applications including WiMAX. It is also observed that size reduction up to $18.3 \%$ in terms of overall size and $23.4 \%$ in terms of the copper cladding is obtained in comparison with a hexagon patch microstrip antenna resonating in the first resonant frequency band.

\section{Conclusion}

The proposed hexagon shaped David fractal microstrip patch antenna has demonstrated its potential for mul- 
ti-band operation. The antenna generates two resonating modes centered at the measured frequencies of 1.79 and $3.385 \mathrm{GHz}$; the first band finds application in GSM mobile phone communication and the second band finds application in WiMAX. The proposed multi-band antenna provides moderate gain and good radiation characteristics.

\section{Acknowledgements}

Authors would sincerely express the gratitude to Mr. Kuruvilla George, Verdant Telemetry and Antenna Systems (P) Ltd. for providing the measurement facilities.

\section{References}

[1] Lee, K.F. (2012) Microstrippatch Antennas-Basic Characteristics and Some Recent Advantages. Proceedings of the IEEE, 100, 2169-2180. http://dx.doi.org/10.1109/JPROC.2012.2183829

[2] Desclos, L., Mahe, Y., Reed, S., Poilasne, G. and Toutain, S. (2001) Patch Antenna Size Reduction by Combining Inductive Loading and Short Point Techniques. Microwave and Optical Technology Letters, 30, 385-386.

http://dx.doi.org/10.1002/mop.1322

[3] Wang, H.Y. and Lancaster, M.J. (1999) Aperture Coupled Thin Film Superconducting Meander Antennas. IEEE Transaction on Antennas and Propagation, 47, 829-836. http://dx.doi.org/10.1109/8.774137

[4] Kan, H.K. and Waterhouse, R.B. (1999) Size Reduction Technique for Shorted Patches. Electronic Letters, 35, 948949. http://dx.doi.org/10.1049/el:19990703

[5] Zhao, G., Zhang, F.S., Song, Y., Weng, Z.B. and Jiao, Y.C. (2007) Compact Ring Monopole Antenna with Double Meander Line for 2.4/5 GHz Dual Band Operation. Progress in Electromagnetic Research, 72, 187-194. http://dx.doi.org/10.2528/PIER07031405

[6] Zhong, J.W., Edwards, R.M., Ma, L. and Sun, X.W. (2013) Multiband Slot Antennas for Metal Back Cover Mobile Hand Set. Progress in Electromagnetic Research Letters, 39, 115-126. http://dx.doi.org/10.2528/PIERL13021901

[7] Liu, Z.Y., Yin, Y.Z., Zheng, S.F., Hu, W., Wen, L.H. and Zou, Q. (2010) A Compact CPW-Fed Monopole Antenna with a U-Shaped Strip and a Pair of L-Slits Ground for WLAN and WiMAX Applications. Progress in Electromagnetics Research Letters, 16, 11-19. http://dx.doi.org/10.2528/PIERL10052706

[8] Lai, Z.H., Yuan, J.D., Yang, X.J., Ye, Z.F. and Chen, W.Q. (2014) Multiband Probe Fed Stacked Patch Antenna for GNSS Applications. Progress in Electromagnetic Research Letters, 49, 131-135. http://dx.doi.org/10.2528/PIERL14092803

[9] Karim, M.N.A., Rahim, M.K.A., Majid, H.A., Ayop, O., Abu, M. and Zubir, F. (2010) Log Periodic Fractal Koch Antenna for UHF Band Applications. Progress in Electromagnetic Research, 100, 201-218. http://dx.doi.org/10.2528/PIER09110512

[10] Li, D.T. and Mao, J.F. (2013) Multiband Multimode Arched Bow Shaped Fractal Helix Antenna. Progress in Electromagnetic Research, 141, 47-78. http://dx.doi.org/10.2528/PIER13050903

[11] Mahatthanajatuphat, C., Saleekaw, S. and Akkaraekthalin, P. (2009) A Rhombic Patch Monopole Antenna with Modified Minkowski Fractal Geometry for UMTS, WLAN and Mobile WiMAX Applications. Progress in Electromagnetic Research, 89, 57-74. http://dx.doi.org/10.2528/PIER08111907

[12] Li, D. and Mao, J.-F. (2012) Sierpinskized Koch-Like Sided Multifractal Dipole Antenna. Progress in Electromagnetic Research, 130, 207-224. http://dx.doi.org/10.2528/PIER12060108

[13] Jagadeesha, S., Vani, R.M. and Hunagund, P.V. (2012) Plus Shape Slotted Fractal Antenna for Wireless Applications. Wireless Engineering and Technology, 3, 175-180. http://dx.doi.org/10.4236/wet.2012.33025

[14] Kushwaha, N. and Kumar, R. (2013) Design of Slotted Ground Hexagonal Microstrip Patch Antenna and Gain Improvement with FSS Screen. Progress in Electromagnetic Research B, 51, 177-199. http://dx.doi.org/10.2528/PIERB13031604

[15] Khan, O.M., Islam, Z.U., Farooq, I.R., Bhatti, A. and Islam, Q.U. (2013) Novel Miniaturized Koch Pentagonal Fractal Antenna for Multiband Wireless Applications. Progress in Electromagnetic Research, 141, 693-710. http://dx.doi.org/10.2528/PIER13060904

[16] Dorastkar, M.A., Islam, M.T. and Azim, R. (2013) Design of a Novel Super Wide Band Circular Hexagonal Fractal Antenna. Progress in Electromagnetic Research, 139, 229-245. http://dx.doi.org/10.2528/PIER13030505

[17] Azari, A. and Rowhani, J. (2008) Ultra Wide Band Fractal Microstrip Antenna Design. Progress in Electromagnetic Research C, 2, 7-12. http://dx.doi.org/10.2528/PIERC08031005

[18] Joseph, S., Paul, B., Mridula, S. and Mohanan, P. (2013) A Novel Planar Fractal Antenna with CPW Feed for Multi- 
band Applications. Radio Engineering, 22, 1262-1266.

[19] Verma, S. and Kumar, P. (2014) Compact Triple Band Antenna for WiMAX and WLAN Applications. Electronic Letters, 50, 484-486. http://dx.doi.org/10.1049/el.2013.4313

[20] Liu, H.W., Ku, C.H. and Yang, C.F. (2010) Novel CPW-Fed Planar Monopole Antenna for WiMAX/WLAN Applications. IEEE Antennas and Wireless Propagation Letters, 9, 240-243. http://dx.doi.org/10.1109/LAWP.2010.2044860

[21] Armin, B. and Shlomo, H. (1994) Fractals in Science. Springer Verlag, Berlin.

[22] Tiwari, H. and Kartikeyan, M.V. (2010) A Stacked Microstrip Patch Antenna with Fractal Shaped Defects. Progress in Electromagnetic Research C, 14, 185-195. http://dx.doi.org/10.2528/PIERC10052903

[23] Mandelbrot, B.B. (1983) The Fractal Geometry of Nature. W.H. Freeman, New York. 